\title{
Au-Pt alloy nanocrystals incorporated in silica films
}

\author{
Goutam De $\dagger$ and C. N. R. Rao* \\ Received 11th August 2004, Accepted 23rd November 2004 \\ First published as an Advance Article on the web 15th December 2004 \\ DOI: $10.1039 / \mathrm{b} 412429 \mathrm{~d}$
}

$\mathrm{Au}, \mathrm{Pt}$ and $\mathrm{Au}-\mathrm{Pt}$ alloy nanocrystals have been prepared in thin $\mathrm{SiO}_{2}$ film matrices by sol-gel spin-coating, followed by heating at $450{ }^{\circ} \mathrm{C}$ in $10 \% \mathrm{H}_{2}-90 \%$ Ar. X-Ray diffraction patterns reveal that the $\mathrm{Au}$ and $\mathrm{Au}-\mathrm{Pt}$ nanocrystals have a preferential (111) orientation. Upon increasing the Pt concentration, part of the Pt does not alloy with $\mathrm{Au}$, but instead forms a shell around the $\mathrm{Au}-\mathrm{Pt}$ alloy core. The alloy composition itself goes up to $\mathrm{Au}(50): \mathrm{Pt}(50)$, and the Pt shells are formed around the alloy above an alloy composition of $\mathrm{Au}(75): \mathrm{Pt}(25)$. The surface plasmon resonance (SPR) band at $544 \mathrm{~nm}$ of Au gradually disappears due to the formation of $\mathrm{Au}-\mathrm{Pt}$ alloys and core-shell structures.

\section{Introduction}

Metal nanocrystals embedded in appropriate glassy hosts are known to exhibit enhanced nonlinear optical properties, with a large intensity-dependent refractive index related to the real part of the third-order susceptibility, $\chi^{(3)} \cdot{ }^{1}$ Such materials have potential optoelectronic applications in optical switching and limiting devices because of the ultrafast nonlinear response. ${ }^{1-3}$ Optical properties of these composites are greatly influenced by the interface between the nanocrystals and the matrix. ${ }^{4}$ Accordingly, the shape, size and composition of the nanocrystals play an important role in modulating the properties. ${ }^{5-8}$ There is considerable interest today in synthesizing $\mathrm{Au}-\mathrm{Pt}$ bimetallic nanoparticles from solution. ${ }^{9-11} \mathrm{Au}-\mathrm{Pt}$ bimetallic nanoparticles supported on inorganic oxides ${ }^{12}$ and zeolites ${ }^{13}$ are also reported for their improved catalytic properties. Of these, $\mathrm{Au}-\mathrm{Pt}$ core-shell type nanoparticles have been prepared by the deposition of Pt on Au or vice-versa ${ }^{9-11}$ Although coreshell $\mathrm{Au}-\mathrm{Pt}$ nanoparticles are formed readily by the solution process, their formation inside a glassy film matrix has not yet been accomplished. For real nonlinear optical applications, however, the nanocrystals have to be embedded in a matrix which can withstand high intensity laser light. Sol-gel derived metal nanocrystals incorporated in $\mathrm{SiO}_{2}$ films are known to exhibit high $\chi^{(3)}$ values with good reproducibility. ${ }^{2}$ In this article we report a sol-gel synthesis of oriented nanoparticles of $\mathrm{Au}$ and $\mathrm{Au}-\mathrm{Pt}$ alloys as well as of core (alloy)-shell (Pt) particles embedded in thin $\mathrm{SiO}_{2}$ films. Such oriented composite nanocrystals belonging to the quantum-size regime embedded in thin transparent $\mathrm{SiO}_{2}$ film could be interesting for nonlinear optical applications.

\section{Experimental}

$\mathrm{Au}, \mathrm{Pt}$ and $\mathrm{Au}-\mathrm{Pt}$ alloy nanocrystals embedded in silica hosts were prepared from sols starting from tetraethylorthosilicate (TEOS), $\mathrm{HAuCl}_{4} \cdot 3 \mathrm{H}_{2} \mathrm{O}, \mathrm{H}_{2} \mathrm{PtCl}_{6} \cdot x \mathrm{H}_{2} \mathrm{O}(40 \% \mathrm{Pt}), n$-propanol,

\footnotetext{
$\dagger$ Permanent address: Sol-Gel Division, Central Glass and Ceramic Research Institute, Jadavpur, Kolkata 700 032, India.

*cnrrao@jncasr.ac.in
}

$i$-butanol and water, by the sol-gel spin-coating technique. The compositions of the films are listed in Table 1. The molar ratio of the metal $(\mathrm{M}=\mathrm{Au}, \mathrm{Au}-\mathrm{Pt}$ or $\mathrm{Pt})$ to $\mathrm{SiO}_{2}$ was kept constant in all the films, being of 6 equivalent $\mathrm{mol} \% \mathrm{M}: 94 \% \mathrm{SiO}_{2}$. The general method of preparation of the films was as follows. To a solution of TEOS in $n$-propanol (50\% of the total) of the appropriate concentration, an aqueous- $n$-propanol solution containing $\mathrm{HAuCl}_{4} \cdot 3 \mathrm{H}_{2} \mathrm{O}$ or/and $\mathrm{H}_{2} \mathrm{PtCl}_{6} \cdot x \mathrm{H}_{2} \mathrm{O}(40 \% \mathrm{Pt})$ was added under stirring, and the stirring continued for $2 \mathrm{~h}$ at $22 \pm$ $2{ }^{\circ} \mathrm{C}$. After this period, $i$-butanol was added and the sol stirred for another $1 \mathrm{~h}$. The total $\mathrm{H}_{2} \mathrm{O} / \mathrm{TEOS}$ molar ratio was maintained at 8 . The total equivalent $\mathrm{SiO}_{2}$ and metal content of the sols was about $4.5 \mathrm{wt} \%$ in all cases. Films were deposited on clean silica glass slides (type II, Heraeus), silicon wafers and ordinary soda-lime glass slides by spin-coating, employing a spinning rate of $1000-1500 \mathrm{rpm}$. The resulting films were dried at $75{ }^{\circ} \mathrm{C}$ in air. The dried films were then heated to $450{ }^{\circ} \mathrm{C}$ for $30 \mathrm{~min}$ in air (to remove the organic matter) and then in $10 \%$ $\mathrm{H}_{2}-90 \% \mathrm{Ar}$ (gas flow was controlled by mass flow controller) for $1 \mathrm{~h}$. The films were allowed to cool naturally in the flow of the $10 \% \mathrm{H}_{2}-90 \%$ Ar gas mixture.

Powder X-ray diffraction (XRD) patterns of the thin film samples were recorded with a diffractometer operating at $40 \mathrm{kV}$ and $30 \mathrm{~mA}$ using Ni-filtered $\mathrm{Cu} \mathrm{K} \alpha$ radiation. Transmission electron microscopy (TEM) was done using a Jeol (model JEM 3010). Optical spectra of the coated films were obtained on a Perkin Elmer UV-VIS spectrophotometer (model Lambda 900). Scanning electron microscopy (SEM) was done using a scanning electron microscope (model Leica S440i).

\section{Results and discussion}

The silica-gel films air-dried at $75{ }^{\circ} \mathrm{C}$ are completely transparent and colourless. $\mathrm{AuCl}_{4}{ }^{-}$and/or a mixture of $\mathrm{AuCl}_{4}{ }^{-}$ and $\mathrm{PtCl}_{6}{ }^{2-}$ ions remain in the gel-films trapped as in other sol-gel derived films. ${ }^{14}$ After heat-treatment of the films at $450{ }^{\circ} \mathrm{C}$ the $\mathrm{AuCl}_{4}{ }^{-} / \mathrm{PtCl}_{6}{ }^{2-}$ ions are reduced, precipitating $\mathrm{Au} / \mathrm{Pt}$ metallic nanoparticles in glassy $\mathrm{SiO}_{2}$ film matrices. It may be noted here that annealing in air could reduce $\mathrm{AuCl}_{4}{ }^{-}$ and $\mathrm{PtCl}_{6}{ }^{2-}$ ions to their corresponding metallic states in individual systems. ${ }^{8,15}$ However, in a mixed system, the large 
Table 1 Composition of the films obtained after annealing at $450{ }^{\circ} \mathrm{C}$ for $1 \mathrm{~h}$ in $10 \% \mathrm{H}_{2}-90 \% \mathrm{Ar}$

\begin{tabular}{lllll}
\hline $\begin{array}{l}\text { Starting composition } \\
\text { (mol } \mathrm{Au}: \text { mol Pt : mol Si) }\end{array}$ & $\begin{array}{l}\text { Sample } \\
\text { name }\end{array}$ & $\begin{array}{l}\text { Composition } \\
\text { (nominal) }\end{array}$ & $\begin{array}{l}\text { Lattice parameter/nm } \\
\text { (XRD) }\end{array}$ & $\begin{array}{l}\text { Calculated alloy composition } \\
\text { from Vegard's law }\end{array}$ \\
\hline $6: 0: 94$ & $\mathrm{Au}$ & $\mathrm{Au}$ & 0.4078 & $\mathrm{Au}$ \\
$4.5: 1.5: 94$ & $\mathrm{Au}_{4.5} \mathrm{Pt}_{1.5}$ & $\mathrm{Au}_{0.75} \mathrm{Pt}_{0.25}$ & 0.4060 & $\mathrm{Au}_{0.75} \mathrm{Pt}_{0.25}$ \\
$3: 3: 94$ & $\mathrm{Au}_{3} \mathrm{Pt}_{3}$ & $\mathrm{Au}_{0.5} \mathrm{Pt}_{0.5}$ & 0.4051 & $\mathrm{Au}_{0.666} \mathrm{Pt}_{0.333}$ \\
$1.5: 4.5: 94$ & $\mathrm{Au}_{1.5} \mathrm{Pt}_{4.5}$ & $\mathrm{Au}_{0.25} \mathrm{Pt}_{0.75}$ & 0.4037 & $\mathrm{Au}_{0.54} \mathrm{Pt}_{0.46}$ \\
$0: 6: 94$ & $\mathrm{Pt}$ & $\mathrm{Pt}$ & 0.3924 & $\mathrm{Au}_{4.5}$ \\
\hline
\end{tabular}

redox potential $(+0.99 \mathrm{~V})$ of the $\mathrm{AuCl}_{4}{ }^{-}$ions could inhibit the reduction process of platinum ions. To avoid this complex situation, films were heated in a reducing atmosphere $\left(\mathrm{H}_{2}-\mathrm{Ar}\right.$ gas mixture), as was also followed by other workers for the preparation of supported $\mathrm{Au}-\mathrm{Pt}$ bimetallic catalysts by reduction of the $\mathrm{HAuCl}_{4} / \mathrm{H}_{2} \mathrm{PtCl}_{6}$ mixture. ${ }^{12 a, 13}$ The heattreated films are homogeneous and transparent. The film containing $\mathrm{Au}$ alone is reddish-blue in colour. The colour gradually disappears on increasing the Pt loading. The film containing $\mathrm{Pt}$ alone is light brown in colour. The thickness of the films, estimated by cross-sectional scanning electron microscopy (SEM) was in the 145-175 nm range.

As also pointed out earlier, one would expect that the gold ions are reduced first, followed by platinum ions since the standard redox potential $E^{0}$ for the $\mathrm{AuCl}_{4}{ }^{-} / \mathrm{Au}^{0}$ couple is higher than that of the $\mathrm{PtCl}_{6}{ }^{2-} / \mathrm{Pt}^{0}$ couple. ${ }^{9,16,17}$

$$
\begin{gathered}
\mathrm{AuCl}_{4}{ }^{-}+3 \mathrm{e}^{-} \leftrightarrow \mathrm{Au}^{0}+4 \mathrm{Cl}^{-} \quad E^{0}=+0.99 \mathrm{~V} \\
\mathrm{PtCl}_{6}{ }^{2-}+4 \mathrm{e}^{-} \leftrightarrow \mathrm{Pt}^{0}+6 \mathrm{Cl}^{-} \quad E^{0}=+0.74 \mathrm{~V}
\end{gathered}
$$

As a result, the $\mathrm{Au}$ nanoparticles form first and the $\mathrm{Pt}$ atoms are deposited on to the gold nanoparticles in the $\mathrm{SiO}_{2}$ film matrix.

Transmission electron microscope (TEM) images of the Au and $\mathrm{Au}-\mathrm{Pt}$ nanocrystals are shown in Fig. 1. The images show the presence of trigonal or prismatic Au nanocrystals with a size range of 10-40 nm [Fig. 1(a)]. The inclusion of Pt causes a drastic decrease in the size of the nanoparticles to $3-4 \mathrm{~nm}$. Interestingly, we observe the presence of a large number of bigger clusters in the case of $\mathrm{Au}_{4.5} \mathrm{Pt}_{1.5}$ [Fig. 1(b)], whereas in $\mathrm{Au}_{3} \mathrm{Pt}_{3}$ the number of such big clusters is reduced [Fig. 1(c)]. In the case of $\mathrm{Au}_{1.5} \mathrm{Pt}_{4.5}$, the bigger clusters are absent [Fig. 1(d)]. Instead, we observe uniform-sized nanoparticles of 3-4 nm.

In Fig. 2, we show the XRD patterns of the $\mathrm{SiO}_{2}$ films containing $\mathrm{Au}, \mathrm{Pt}$ and $\mathrm{Au}-\mathrm{Pt}$ alloy nanocrystals deposited on silica glass substrates. The patterns show only the (111) Bragg reflection, ${ }^{18}$ indicating a highly oriented growth of the nanocrystals. The other Bragg reflections are hardly visible. The decrease in the $d(111)$ value with increasing Pt loading is consistent with the formation of $\mathrm{Au}-\mathrm{Pt}$ solid solutions (Table 1). Thus, in the case of $\mathrm{Au}$ the (111) reflection is at $2.354 \AA$ corresponding to $a=0.4078 \mathrm{~nm}$, while in $\mathrm{Au}_{4.5} \mathrm{Pt}_{1.5}$ it is at $2.344 \AA$ corresponding to $a=0.4060 \mathrm{~nm}$. The $a$ value calculated from Vegard's law for $\mathrm{Au}_{0.75} \mathrm{Pt}_{0.25}\left(\mathrm{Au}_{4.5} \mathrm{Pt}_{1.5}\right)$ is $0.4060 \mathrm{~nm} .{ }^{19,20}$ For $\mathrm{Au}_{3} \mathrm{Pt}_{3}$ and $\mathrm{Au}_{1.5} \mathrm{Pt}_{4.5}$, the observed $d$ values are at 2.339 and $2.331 \AA$ respectively corresponding to $a$ values of 0.4051 and $4037 \mathrm{~nm}$ respectively. These values are higher, indicating a lower Pt content than indicated by the nominal composition of the solid solution (Table 1). In these cases, the $a$ values calculated from Vegard's law give the compositions as $\mathrm{Au}_{0.666} \mathrm{Pt}_{0.333}$ and $\mathrm{Au}_{0.54} \mathrm{Pt}_{0.46}$ respectively. It appears that in the latter, a major proportion of the $\mathrm{Pt}$ atoms does not enter the alloy structure. It may be noted that bulk $\mathrm{Au}-\mathrm{Pt}$ solid solutions are generally formed only at temperatures above $1100{ }^{\circ} \mathrm{C}$.

The compositions of the alloys derived from the respective $d$ values obtained from the XRD patterns are listed in Table 1. By simple arithmetic, we see that about 50 and $66 \mathrm{~mol} \%$ of the $\mathrm{Pt}$ remains out of the solid solutions in $\mathrm{Au}_{3} \mathrm{Pt}_{3}$ and $\mathrm{Au}_{1.5} \mathrm{Pt}_{4.5}$ respectively. The XRD peaks in these systems should therefore show the Pt reflection as well. We, do not, however, see a peak due to Pt because of the small particle size (see Fig. 2 in the case of pure $\mathrm{Pt}$ ).

Fig. 3 shows the optical spectra of the films annealed at $450{ }^{\circ} \mathrm{C}$ for $1 \mathrm{~h}$ in $10 \% \mathrm{H}_{2}-90 \%$ Ar. The pure Au film shows a band at $544 \mathrm{~nm}$ with a broad tail extending towards higher wavelengths due to surface plasmon resonance (SPR). The SPR band of well-dispersed spherical Au nanocrystals is generally sharp and appears around $520 \mathrm{~nm}$. The broadening of this band at higher wavelengths may be due to the anisotropy of the trigonal/prismatic shape (non-spherical) of the Au nanocrystals. ${ }^{6,21}$ The pure Pt film does not have a
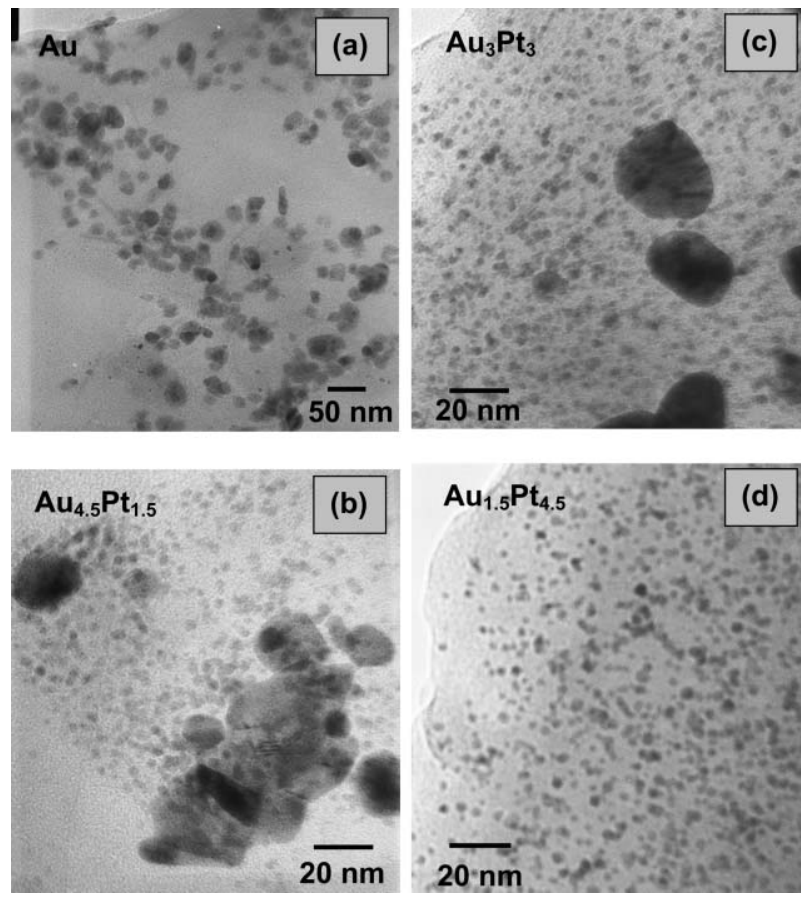

Fig. 1 TEM images showing the nanoparticles embedded in $\mathrm{SiO}_{2}$ films: (a) $\mathrm{Au}$, (b) $\mathrm{Au}_{4.5} \mathrm{Pt}_{1.5}$, (c) $\mathrm{Au}_{3} \mathrm{Pt}_{3}$ and (d) $\mathrm{Au}_{1.5} \mathrm{Pt}_{4.5}$. The alloy compositions are nominal (see Table 1). 


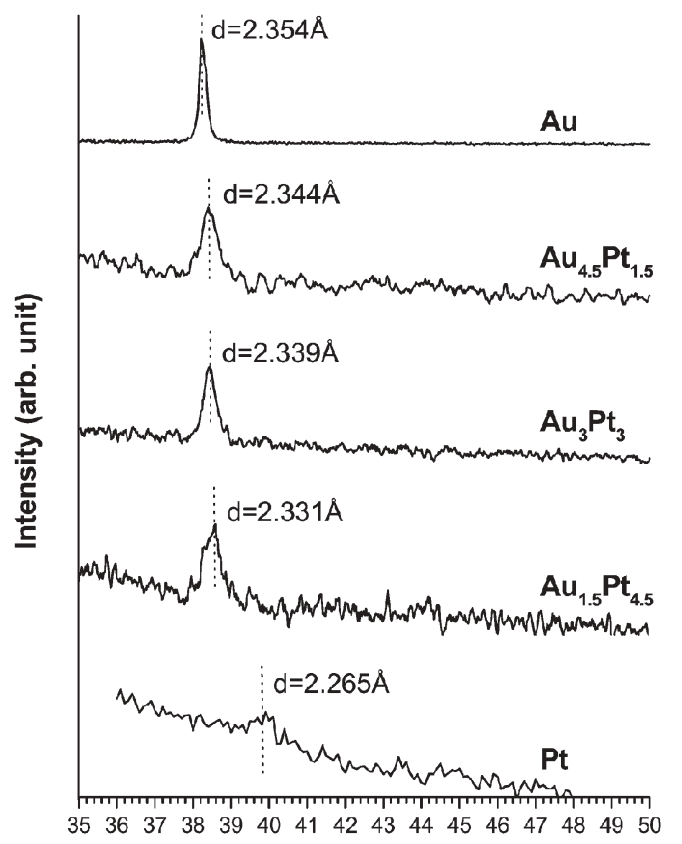

$2 \theta$ (degree)

Fig. 2 XRD patterns of nanocrystals of $\mathrm{Au}$, $\mathrm{Pt}$ and $\mathrm{Au}-\mathrm{Pt}$ alloys embedded in $\mathrm{SiO}_{2}$ thin film matrices. Nominal compositions of the alloys are shown (see Table 1).

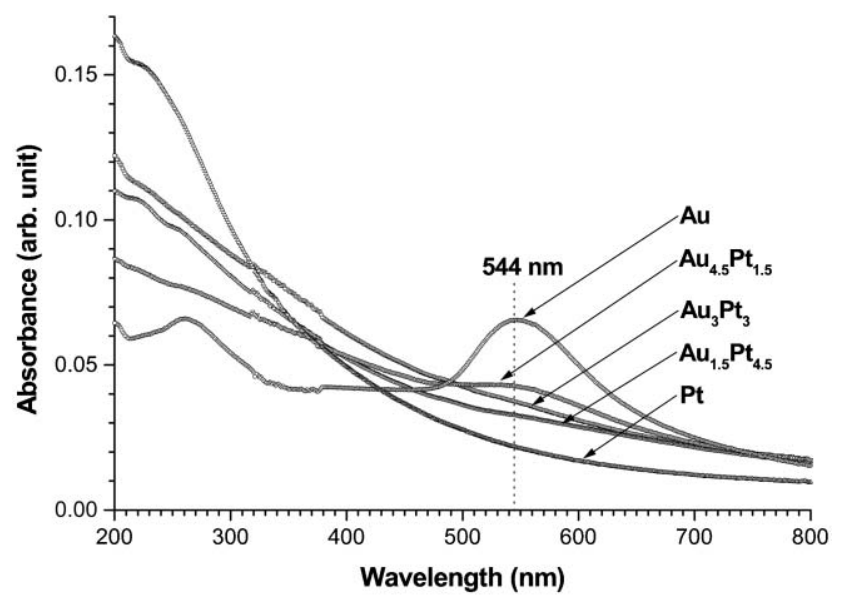

Fig. 3 Optical absorption spectra of $\mathrm{Au}$, Pt and Au-Pt alloys embedded in $\mathrm{SiO}_{2}$ thin film matrices.

distinguishable SPR band. The dampening of the Au SPR band due to the introduction of $\mathrm{Pt}$ indicates the formation of either a $\mathrm{Au}-\mathrm{Pt}$ solid solution or a $\mathrm{Au}$ core-Pt shell type structure. Since the calculated and observed lattice parameters agree well in the case of $\mathrm{Au}_{4.5} \mathrm{Pt}_{1.5}$ (Table 1), we suggest that this is a good solid solution rather than a Au core-Pt shell. For $\mathrm{Au}_{3} \mathrm{Pt}_{3}$ and $\mathrm{Au}_{1.5} \mathrm{Pt}_{4.5}$, the optical spectra show that the Au-SPR band is very weak or absent. This observation may be taken to indicate either the formation of a $\mathrm{Au}-\mathrm{Pt}$ solid solution or a Au core- $\mathrm{Pt}$ shell type structure. However, in $\mathrm{Au}_{3} \mathrm{Pt}_{3}$, the $a$ value calculated from Vegard's law gives the composition of the alloy to be $\mathrm{Au}_{0.666} \mathrm{Pt}_{0.333}$ showing that about $50 \mathrm{~mol} \%$ of the $\mathrm{Pt}$ remains outside the $\mathrm{Au}-\mathrm{Pt}$ alloy. Similarly, in the case of $\mathrm{Au}_{1.5} \mathrm{Pt}_{4.5}$, the d(111) value is consistent with formation of

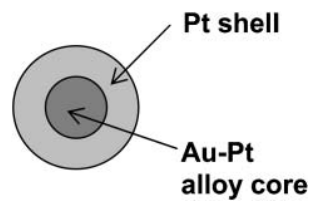

Fig. 4 Schematic diagram of a core (Au-Pt alloy)-shell (Pt) nanocrystal.

the $\mathrm{Au}_{0.54} \mathrm{Pt}_{0.46}$ core with about $66 \%$ of the $\mathrm{Pt}$ remaining as the shell. The core-shell type structure is shown schematically in Fig. 4.

It is of interest to know whether the $\mathrm{Au}, \mathrm{Au}-\mathrm{Pt}$ alloy and $\mathrm{Pt}$ nanoparticles remain as separate clusters in the thin film silica matrix. It was pointed out earlier that the Au nanoparticles are formed first, with the Pt atoms precipitating on to the gold nanoparticles. The Pt atoms close to the Au atoms would be expected to form solid solutions under the experimental conditions. When the $\mathrm{Pt}$ concentration is low (as in $\mathrm{Au}_{4.5} \mathrm{Pt}_{1.5}$ ), we obtain only a $\mathrm{Au}-\mathrm{Pt}$ solid solution while in $\mathrm{Au}_{3} \mathrm{Pt}_{3}$ and $\mathrm{Au}_{1.5} \mathrm{Pt}_{4.5}$ part of the $\mathrm{Pt}$ forms a solid solution with the $\mathrm{Au}$, the remaining part forming a shell around the alloy. The deposition of $\mathrm{Pt}$ atoms on to the surface of the gold nanoparticles can be understood from the optical spectra of the composite films as well. A significant dampening of the gold surface plasmon resonance is known to occur by a surface layer of platinum. ${ }^{9-11}$ This is clearly evidenced in the absorption spectra of the annealed films shown in Fig. 3. The SPR band of gold $(544 \mathrm{~nm})$ gradually disappears with increasing $\mathrm{Pt}$ content. If a mixture of discrete $\mathrm{Au}$ and $\mathrm{Pt}$ nanoparticles were present, the Au SPR band would continue to occur in the $\mathrm{Au}-\mathrm{Pt}$ films.

\section{Conclusions}

$\mathrm{Au}, \mathrm{Au}-\mathrm{Pt}$ alloys and core (alloy)-shell (Pt) nanoparticles have been generated in glassy silica films by the sol-gel method. The nanoparticles are oriented in the (111) crystalline plane. By the low-temperature method employed, nanocrystal alloys are formed up to a $\mathrm{Au}: \mathrm{Pt}$ ratio of about $1: 1$, but with an increase in Pt content, Pt shells are formed around the alloy cores. Formation of $\mathrm{Au}, \mathrm{Pt}$ and their alloy nanoparticles in the silica film matrix is noteworthy and could be of potential technological value.

Goutam De† and C. N. R. Rao*

Chemistry and Physics of Materials Unit, Jawaharlal Nehru Centre for Advanced Scientific Research, Jakkur P.O., Bangalore 560 064, India. E-mail: cnrrao@jncasr.ac.in

\section{References}

1 H. Hache, D. Ricard and C. Flytzanis, J. Opt. Soc. Am. B, 1986, 3, 1647; C. Flytzanis, F. Hache, M. C. Klein, D. Ricard and Ph. Roussignol, Prog. Opt., 1991, 29, 321; T. Tokizaki, A. Nakamura, S. Kaneko, K. Uchida, S. Omi, H. Tanji and Y. Asahara, Appl. Phys. Lett., 1994, 65, 941.

2 G. De, L. Tapfer, M. Catalano, G. Battaglin, F. Caccavale, F. Gonella, P. Mazzoldi and R. F. Haglund, Jr., Appl. Phys. Lett., 1996, 68, 3820andP. P. Kiran, G. De and D. N. Rao, IEE Proc.-Circuits Devices System, 2003, 150, 559.

3 Y.-P. Sun, J. E. Riggs, K. B. Henbest and R. B. Martin, J. Nonlinear Opt. Phys. Mater., 2000, 9, 481. 
4 P. N. Butcher and D. Cotter, The Elements of Nonlinear Optics, Cambridge University Press, Cambridge, UK, 1990; J. A. Creighton and D. G. Eadon, J. Chem. Soc., Faraday Trans., 1991, 87, 3881; F. Gonella, G. Mattei, P. Mazzoldi, G. Battaglin, A. Quaranta, G. De and M. Montecchi, Chem. Mater., 1999, 11, 814; R. H. Doremous, Langmuir, 2002, 18, 2436.

5 U. Kreibig and M. Volmer, Optical Properties of Metal Clusters, Springer-Verlag, Berlin, 1995.

6 A. I. Kirkland, D. A. Jefferson, D. G. Duff, P. P. Edwards, I. Gameson, B. F. G. Johnson and D. J. Smith, Proc. R. Soc. London, Ser. A, 1993, 440, 589.

7 C. N. R. Rao, G. U. Kulkarni, P. J. Thomas and P. P. Edwards, Chem. Eur. J., 2002, 8, 29.

8 G. De, G. Mattei, P. Mazzoldi, C. Sada, G. Battaglin and A. Quaranta, Chem. Mater., 2000, 12, 2157.

9 L. M. Liz-Marzán and A. P. Philipse, J. Phys. Chem., 1995, 99, 15120 .

10 C. Damle, K. Biswas and M. Sastry, Langmuir, 2001, 17, 7156.

11 A. Henglein, J. Phys. Chem. B, 2000, 104, 2201.

12 (a) A. Vázquez-Zavala, J. García-Gómez and A. Gómez-Cortés, Appl. Surf. Sci., 2000, 167, 177; (b) H. Lang, S. Maldonado,
K. J. Stevenson and B. D. Chandler, J. Am. Chem. Soc., 2004, 126, 12949.

13 G. Riahi, D. Guillemot, M. Polisset-Thfoin, A. A. Khodadadi and J. Fraissard, Catal. Today, 2002, 72, 115.

14 G. De and D. Kundu, Chem. Mater., 2001, 13, 4239.

15 H. Kozuka, G. Zhao and S. Sakka, J. Sol-Gel Sci. Technol., 1994, 2, 741; G. Fóti, C. Mousty, K. Novy, Ch. Comninellis and V. Reid, J. Appl. Electrochem., 2000, 30, 147.

16 R. C. Weast, Handbook of Chemistry and Physics, 56th edn., CRC Press, Cleveland, OH, 1975, p. D-141.

17 A. I. Vogel, Quantitative Inorganic Analysis, 3rd edn., Addison Wesley Longman Ltd, England, 1961, p. 87.

18 D. F. Leff, L. Brandt and J. R. Heath, Langmuir, 1996, 12, 4723.

19 M. Hansen, Constitutions of Binary Alloys, McGraw-Hill, New York, 1958.

20 H. Okamoto, D. J. Chakrabarti, D. E. Laughlin and T. B. Massalski, Phase Diagrams of Binary Gold Alloys, Monograph Series of Alloy Phase Diagrams, ASM Internationals, Metals Park, OH, 1987.

21 G. De and C. N. R. Rao, J. Phys. Chem. B, 2003, 107, 13597. 